\title{
COMMUNICATION PROCESSES IN A PROJECT IMPLEMENTED BY A PUBLIC INSTITUTION Mateusz $\mathrm{Kot}^{1}$
}

\begin{abstract}
The study aims at defining communication relations between a project team, a project manager and a wider project environment within a public institution. Individual in-depth interviews were chosen as the research method. On the basis of the collected material, five main issues related to the communication processes in the studied project were specified: a hierarchical structure, professional dependence, understanding of one's mutual duties, relations between members of the project team and communication with the steering committee. On the basis of the findings, a scheme of project management in the studied public institution was identified. Communication and organizational weaknesses have been indicated, which may be eliminated or may not occur if they are spotted early on.
\end{abstract}

Keywords: public institution, communication, project management

\section{Introduction}

Communication sciences go far beyond the fields they are directly correlated with [Jabłonowski \& Mielczarek, 2018]. As J. Fiske [2003] assumes, research on communication cannot be separated from the knowledge of a given culture. In this paper, we will look at the patterns of communication processes in the project environment, which are based on those derived from the communication sciences. Assigning the roles of a recipient and a sender to the project stakeholders [Trocki, 2012] seems to be the same as the concept of transmitting and receiving messages including encoding and feedback compression [McQuail, 1987].

Well managed communication leads to effective implementation of the project team's work [Zulch, 2014]. The project manager, who is in a specific communication position, is responsible for its implementation. Firstly, he or she communicates in both directions in the vertical hierarchy. It is two-way communication, i.e. from top to bottom, and in the opposite direction. The project manager has his/her superiors, a steering committee, the management of the institution in which he/she works, and on the other hand the founder - sometimes an external one. They all have their expectations and goals to be achieved through the project, and the project manager becomes a kind of repre-

Mateusz Kot, PhD at Cardinal Stefan Wyszyński University in Warsaw, Institute of Media Education and Journalism, ul. Dewajtis 5, 01-815 Warsaw; e-mail: m.kot@uksw.edu.pl, ORCID: 0000-0001-9933-8420. 
sentative of their goals [Turner \& Müller, 2004]. Employees, on the other hand, send out messages or feedback, which also passes by the project manager, yet this time upwards. The manager located in this place must filter the messages and provide information properly in order to act effectively in favour of the project implementation. The manager also communicates horizontally, e.g. with department heads or people who are not in a hierarchical business relationship. This involves a need to select other methods of communication, while pursuing the same goal - a successful project implementation.

Not only should the project manager know how to communicate effectively, but he or she should also have management skills (including project management) and specialist knowledge of the subject of the project. Having communication skills is considered by project managers to be an essential skill of a project manager. It is followed by skills related to organization and team building. It turns out that the communication process may take up to $90 \%$ of the project manager's working time [Kandefer-Winter \& Nadskakulska, 2016].

In order to organize the communication processes within the project, intervention of the project manager is needed from the very beginning. Each of the team members should learn details of the main areas the project manager should pay special attention to [Grucza, 2012]:

- emphasis on proper motivation of the project team, integration of team members; "

- presentation of the project plan, objectives, the roles of the project members, division of their responsibilities;

- defining the ways of communication in the project horizontally and vertically.

The literature describes the conditions for conducting projects, also in public institutions. For the purposes of this paper, it is worth explaining that a project should be understood as an undertaking whose components are complex activities that give it a unique character. It has a timeline with a specified start and end [Madamuss, 2000]. It involves certain resources, most often used for teamwork. The entire process is aimed at achieving a specific goal or indicator [Trocki, 2015]. It features uniqueness, participation of many people, complexity and scale of the undertaking. It is innovation-oriented, has a specific organizational structure and a clearly defined goal-oriented approach [Pawlak, 2006].

Considering the concept of a project in the context of a given organization, it is defined as an undertaking not previously encountered in the organization, a new one, and different from standard and routine activities. Implementation of a project by a given organization does not exclude the possibility of building a project team consisting of representatives of various organizations or employing people from outside the organization only for the project implementation [Pawlak, 2006]. This results from the need to use unique specialist skills, not always available within a given organisation.

Introducing work based on project management to public organisations may be connected with employees' reluctance because of breaking the routine, as well as the necessity of constant improvement of their competences, increased workloads and changing the way they work [Prawelska-Skrzypek, 2011]. It is the human factor that is considered to be the greatest challenge in the effective implementation of projects in public institutions. In order to increase the number of projects in the public sector, and thus to prepare it for the current situation on the private market, a scheme is applied which consists in encouraging them to do so not through coercion but through the possibility of additional benefits. It means that public institutions seeking to obtain funding for specific initiatives must implement them through implementation of projects, since this is the only way in which these actions will be financed [Jałocha, 2014].

D.W. Wirick [2009] identifies the greatest threats to project implementation in public institutions: 
- No clear, direct relationship between an employee's performance and his or her reward;

- Lack of independence for the project manager to select the people hired for the project - often the majority of them must be recruited from the institution within which the project is implemented;

- No work culture focused on taking reasonable risks and actions beyond those required to eliminate the problems encountered in the project;

- Limited possibilities of the remuneration system, which does not ensure financial terms to retain the best employees within the project or institution;

- Lack of focus on results-oriented project work in the working environment;

- Dealing with internal or external stakeholders from the political arena.

Public organisations are also characterised by a management approach based on a strict vertical hierarchy. Introducing the project implementation to the organization is connected with a necessity to adjust the management within the project, often by changing the hierarchical structure. Moreover, delegating employees to participate in a project is connected with limiting their work in an institution or abandoning it for the period of the project [Pawlak, 2006].

\section{Materials and methods}

The study was carried out in a public institution whose part of its activity consists in implementing projects financed from external sources, public or private. The purpose of the research was to determine the communication relations between the project members, the project manager and the external environment in relation to the project, but remaining within the organization. On the basis of the collected material, potential errors or difficulties in effective communication within the project scope were to be observed. Identifying them may help to eliminate these problems or avoid them when implementing other projects in public institutions.

The main areas that were to be diagnosed in the study were: the communication model between those involved in the project, positive or negative factors shaping the communication process within the project and the way the employee communicates with two managers - the head of the department and the project manager.

The literature on the subject allows us to formulate the following hypotheses: $\mathrm{H} 1$ in the institution under study, communication processes in the project are disturbed as a result of the fact that a strict hierarchical structure has been abandoned for the needs of project implementation; $\mathrm{H} 2$ - the employees know the need for flexibility of tasks in the project work, yet they are reluctant to apply it in practice.

The use of qualitative interviews allows us to recognize subjective feelings of the respondents as well as let them present their thoughts more broadly [Babbie, 2006]. Each respondent communicates his or her own subjective vision of reality, and thus may emphasize aspects that are particularly important to him or her. The sensitive issues raised can be developed and clarified [Wimmer \& Domimick, 2006]. This also indicates a very local character of the results, which can be related only to the studied aspect of the reality [Creswell, 2013] - a specific project.

In such a limited approach, this study should be understood as a case study. It may be considered as a pilot one or as a reason to carry out quantitative studies on a representative sample in order to confirm or refute the uniqueness of the observed situation.

The interviews were conducted at the workplace of the respondents, in a separate, closed room where only the respondent and the interviewer were present during the study. Before starting the study, each person was informed about the possibility to withdraw at any time, the purpose of the study, the method of storing the recordings and the rules concerning the concealment of identity of both the person and the data influencing 
the possible identification of the institution.

Nine respondents participated in the study, including the project manager, which constitutes more than half of the project team. They were employed in a total of 7 departments. The respondents worked as: junior specialist, specialist, senior specialist and chief specialist.

Within the institution, the project was implemented in a matrix structure, consisting in delegating employees of various specialisations already employed to particular project tasks, while at the same time performing tasks assigned to their positions. Additionally, employees were hired only for the project and they were included in the structure of the organisation by assigning them to the already existing departments in the institution. This structure is characterised by two power centres - project managers and heads of department. It is a combination of a project structure and a traditional linear structure [Pawlak, 2006]. In other words, it means that an employee has two superiors who have a formal possibility to give him/her official orders. Both the manager and the head were involved in the recruitment process and decided whether to hire them or not. Additionally, it should be noted that the decision on the amount of bonuses is made by the head of the department, after a possible consultation with the project manager.

For the purposes of the further part of this paper, the following abbreviations will apply:

- PM - project manager,

- MP - member of the project not being a coordinator of the area,

- HD - Head of Department,

- AC - area coordinator who is a project member,

- SC - Steering Committee.

\section{Results}

\section{a. Self-assessment of employees}

Respondents were asked to self-assess their way of communicating. The answers were not relatively varied and the worst self-esteem was "relatively communicative". The vast majority believed that they did not have any problems contacting one another and often estimated communication only as a tool to contribute to specific goals and tasks related to the work. The majority admits that there are certain qualities in others that make the process of effective communication much more difficult.

The most common obstacle in relations with other team members was described as "chaos", although its definition was different for each person using the term in relation to the way the other person communicates. One participant interprets it as a lack of specific communication schemes, its form or rules. Another refers to the way information is communicated, i.e. in a disorganized, dynamic, and multithreaded way.

The employees of the institution directed to perform some of the project tasks note that there are stereotypes in the perception of specific departments and their work organisation or communication. The opinion about particular departments seems to be consistent from the point of view of the respondents. It differs only in the assessment of their own department, as everyone evaluates it positively.

When determining the quality of communication processes between people in the project, the respondents assess it as good or very good. They consider themselves to be a good team with people who create a good working atmosphere. Negative opinions are given to individuals who, according to the respondents, do not carry out their duties, which results in an increase in the tasks of other team members.

The respondents also commented on the project. Two main positions are clearly 
outlined. The division appeared to be based on the nature of employment of the respondents. Employees of the institution, delegated to the project, but still performing their duties related to their permanent job, define the hierarchical structure of the project as innovative and unprecedented in the institution so far. There has not yet been a situation in which a project is not implemented in a specific department and the head of the department (HD) is not at the same time the project manager (PM). A new structure was created to appoint a PM that is not a HD and to give him/her a team of people from other departments.

Employees hired to work in a project, whose period of employment in the institution is the same as the working time in the project, believe that the project they are implementing is one of many implemented by the institution employing them, and it is not something new, or organisationally innovative.

\section{b. Basic forms of communication in the project}

The respondents mention two forms of communication in the project as basic ones. The first one is a business e-mail, the second one is a department meeting. There is no dominant form among them. They are considered to be necessary for carrying out the employees' tasks and achieving indicators that will allow the project to be considered completed.

Employees feel a need for weekly department meetings. They indicate that there was no such practice in the project at the beginning, and this has changed over the course of the project. PM notes that initially the meetings were held once a month, but later the frequency was increased to one per week. According to PM, the department meetings attended by all project members are intended, among other things, to integrate the environment, which was noted after the increased frequency of meetings. The number of personal conflicts decreased, and the level of intimacy between the employees increased. The employees evaluated the change as improving the way they communicate within the project.

The respondents emphasized the importance of department meetings. They note that they mainly perform informational and organizational functions. Several people are satisfied with the form and course of the meetings. Some, however, show aspects that reduce their quality, such as no clear agenda, which may result in turning a meeting into a discussion, sometimes in subgroups; they await a general discussion - between all the attendants.

They point out that there is a need for clear leadership during the meeting, animating the participants, perhaps a need to increase the use of the workshop method, involving, and activating one. The workshop methods were used several times, which significantly influenced attractiveness and involvement during the meetings. The employees stress that they lack a summary of the meeting in the form of an e-mail. It is necessary to appoint one person as a kind of the secretary during the meeting, whose task would be to send a memo to all the participants in the project structuring the arrangements and tasks. The respondents believe that this would make it possible to prioritize particular tasks.

The second most important form of communication in the project is e-mail. It is considered to be a tool for organizing work and helping to prioritize tasks. A few people also indicate the need to document the decisions and commitments of other employees so that in future they can have a basis to require their realization. Email box is also a kind of an archive that can be used in disputes.

However, the importance of electronic mail decreases in the immediate work environment - in a team dealing with one task. This form of communication is often resigned from there, and its place is taken by oral arrangements. However, this concerns only two or three-person teams. There were also no cases of similar relations between depart- 
ments.

c. Knowledge of the responsibilities of the project participants

The respondents believe that they do not know the competences and duties of other people involved in the project. They have a problem with determining their responsibility for particular tasks, which results in uncertainty about the activities they perform. They cannot clearly identify who is responsible for a specific task, who is coordinating it and what they can expect from whom when engaging in cooperation in the implementation of their activity.

There are people who have a job based on the repetition of routine activities. In these cases, the conditions of cooperation are defined or developed during the implementation. The problem is the tasks appearing during the project implementation, which are additional ones, and unplanned in the initial schedule. It is difficult for the respondents to determine who is responsible for them and whose duties include their implementation.

A department meeting at the beginning of the project, during which the scope of responsibilities and tasks of each of the project members would be defined in detail, would improve the recognition of their mutual obligations.

There seems to be a widespread awareness of the need for task flexibility to adapt to new requirements and unforeseen situations in the project space. On the other hand, in case there are any uncertainties regarding an increase in their responsibilities, the employees refer to the provisions of their job contract. They can be quoted during competence disputes or in case of division of new tasks.

\section{d. Communication processes in the department}

The structure of the studied public institution assumes that the employee in the project (PM) has two managers, i.e. PM and HD. The HD indicates that the communication process takes place in a clearly defined scheme, which can be described as linear. It is directly related to the structure of the hierarchy in the project. PM provides information to the employees acting as Area Coordinators (AC), who in turn are responsible for distributing the messages further, to other PMs. In some departments, an AC has not been appointed and sometimes an AC is the only staff member of the area in the project, as shown in Figure 1.

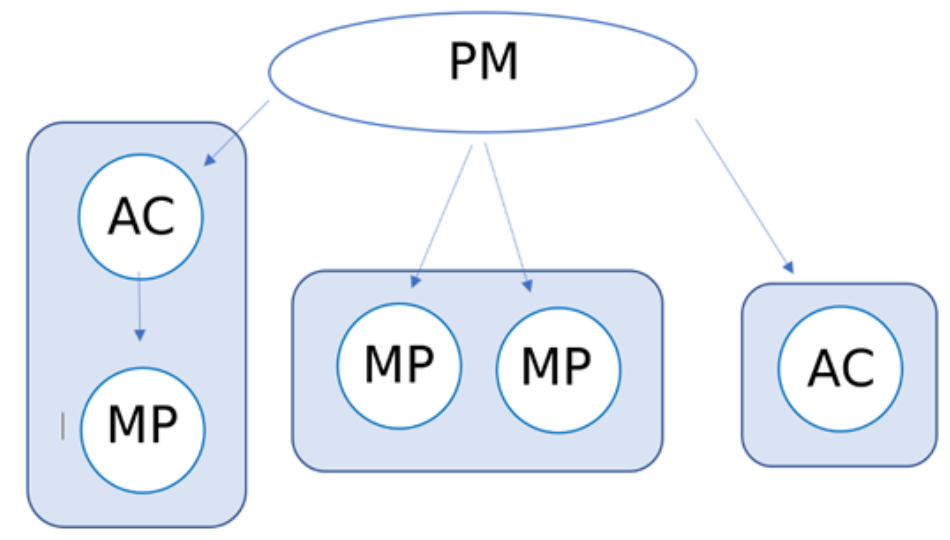

Figure 1: Communication processes in the project according to PM, own study

The data collected indicate, however, that the communication diagram for PM, AC, MP is not justified in practice. According to MP, the differentiation of positions as junior specialist, specialist, senior specialist does not affect the position in the communication process and professional dependence. They note that there is no justification for distinguishing AC. In extreme cases, this hierarchy is individually recognised or not, based on subjective opinions in terms of professional subordination and the impact on the assign- 
ment of tasks, also in relation to PM.

Communication processes in the project are also shaped by the HD. It depends on the role that the head of the department plays or wants to play in the project, as well as the scope of his or her influence on the tasks performed by the employee and appointing additional employees.

The role of PM is important in the communication process within the project because of his/her relationship with AC and PM. The respondents employed only for the project declare that the tasks set by the PM are superior to the ones assigned by HD, although they also know that the HD was responsible for their recruitment and it is his or her competence to determine the amount of bonuses granted. This can be influenced by the opinion of PM, but it is not binding. A different approach is presented by PMs, who are delegated to participate in the project, and they only perform part of their duties. In such cases, the tasks delegated by the HD are predominant.

On the basis of the interviews, the following communication schemes in particular departments were developed, taking into account the HD who has a significant influence on the communication processes and the scope of work of the AC and MP. However, the level of involvement of HDs in the project varies, and thus their roles are also different.

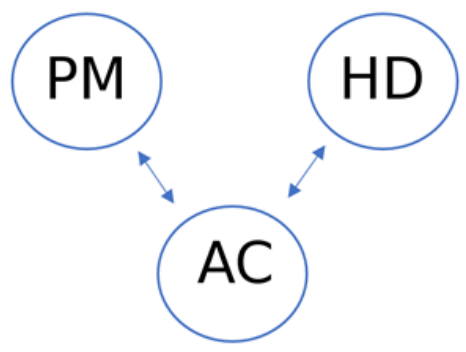

Figure 2: Communication processes in Department 1, own study

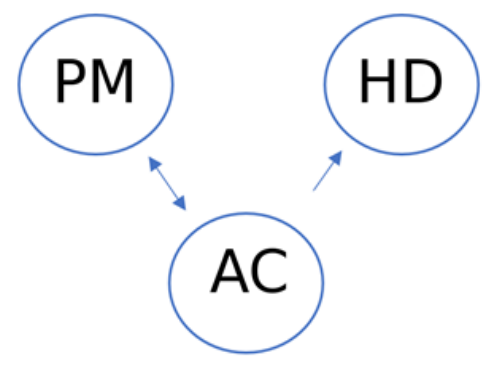

Figure 3: Communication processes in Department 2, own study

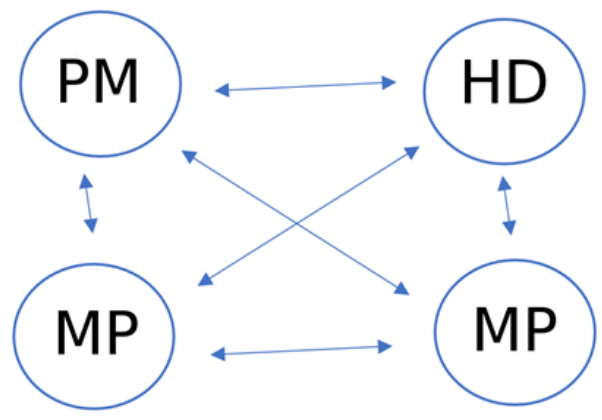

Figure 4: Communication processes in Department 3, own study 


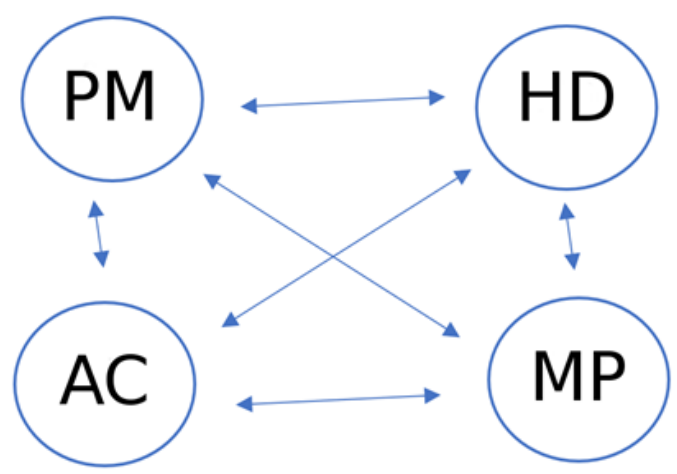

Figure 5: Communication processes in Department 4, own study

A similarity can be observed in the work of the diagrams designed on the basis of the interviews. The first pair concerns the situation when PM and HD do not communicate with each other or do it only occasionally. In such a situation, the employee acts as an intermediary of a message (Fig. 2) or is required to report on the activities he/she performs in the project (Fig. 3).

The second pair of diagrams shows no difference between the communication process in the case of equal positions in the department and the one in which the AC is listed. The diagram assumes communication between each of them without acting as an intermediary or superior in the hierarchy between PM and MP. This indicates that the function of $A C$ is equal to that of MP in the communication process.

\section{e. Role of the Steering Committee}

The last point raised was the relationship with the Steering Committee (SC). Some of the respondents do not feel the need to communicate with this project body. They believe that the tasks they perform are firm and consistent in their form and require no consultation. The goals designed at the beginning are perceived to be fixed.

Those employed for tasks which are changeable or increasing in their number feel dissatisfied with the communication with SC, also direct one. They indicate the need for meetings attended by AC, MP, PM and SC. This will make it possible to clearly define the expectations of the SC with respect to the tasks performed, their details and implementation. According to the employees of the institution who had been employed before the project was launched, it has been the first project where the number of meetings with the $\mathrm{SC}$ is so limited. This was not the case in previous years.

In most cases, the respondents have problems with determining the role of SC in the project and do not know its contribution to the project. They notice that PM is responsible for communication with SC, but there are situations when it is carried out without the intermediary of PM, but on the SC and AC line.

\section{Discussion}

The first visible issue is the self-esteem of the participants. Within the institution there is a clear division into departments that create their own communication culture. Belonging to a department allows to communicate with others from the perspective of a group, usually perceived positively by its members. There are cases when a set of characteristics assigned to another group evolves into a stereotype that seems to be common throughout the institution. This refers to different ways of communication and work organisation, which is created at the level of the department, i.e. the responsible head of the department. This underlines the significance of this role as a person who has to ensure proper inter-departmental integration and create ad hoc communication with his or her department based on the solutions developed with the external environment.

There is also a very strong commitment to formalising messages by transferring 
them into e-mails. Arranging and taking up new tasks, or a report on the current tasks, should be preferably reflected in an email that can be archived, used as a reminder, argument in a dispute or as a kind of safeguard against possible consequences. At the same time, it can be observed that this form of communication has been abandoned. In the case of small groups, oral communication, which does not require confirmation by e-mail, is acceptable. It is considered equally important and binding. However, it is not used outside such groups, usually linked with a long-term, routine task.

An e-mail, as a means of communication, clearly interferes with department meetings. The respondents believe that each meeting should be summed up by e-mail. In fact, this may improve the definition of tasks, or be an outline of the course of the meeting for those absent. However, it plays the same role as other e-mails. The respondents also observe that notes should be taken, although they do not clearly indicate the person who should be responsible for it. None of the respondents volunteered to do so.

One can observe the awareness of the evolution of the frequency of department meetings within the project team. The respondents assess this phenomenon positively, and the PM observations allow to distinguish the function of team integration and increase its efficiency by devoting less time to potential conflicts. An attempt to improve the communication process by increasing the frequency of meetings shows that the project members work on improving their performance and evaluate the effects of such changes.

The most serious consequence of communication problems is that the respondents do not recognise their mutual competences properly. The indicated lack of a clear division of responsibilities at the beginning of the project proved to have an impact on the communication problems in its later stages. MP and AC seem to see a need to adapt to changeable and new tasks. However, they still refer to their contracts and the rigid provisions contained therein in situations of doubt or requiring a closer hierarchical relationship. An extreme situation is that of a discretionary approach to sovereignty, even in relation to PM. This poses a risk of not fulfilling the tasks. This may indicate a tendency for inflexibility typical of public institutions, which has been formulated as H2. Despite the declarative knowledge of the principles of work in the project environment, in some cases the stagnant culture of work in a public institution is applied.

There is also a gap between the communication scheme outlined by PM and the others. Theoretically, the flow of the message is linear, based on the hierarchy, but in practice it strives for an "everyone with everyone" relationship. Employees who have an $\mathrm{AC}$ in their department do not recognise them as a superior, but want to see them as a peer.

Another challenge for communication in the project is when project members are assigned to departments already existing in the institution. In this case, they have two managers: PM and HD. The proposed communication schemes allow us to observe that in each department the communication process is unique. This confirms the situation indicated in $\mathrm{H} 1$ - a lack of a new and uniform structure for the needs of the project contributes to the lack of effective communication, different in each of the studied departments.

The possibility of making decisions by the HD as well as the tools and capabilities he or she possesses, i.e. hiring an employee and determining the amount of his or her bonus, may have a direct impact on the decisions made by the employee and setting the priorities of tasks. Transferring these competencies to PM would allow him or her to gain a much stronger position in the project, as well as to have not only influence but also full decision-making power in the assessment of his or her subordinates. This could translate into the effects of their work, which would largely coincide with the project tasks.

The role of SC is also under discussion. It has a real impact on the way the tasks are performed. However, the respondents are divided as to whether the communication with 
the SC should be conducted through the PM or whether there should be direct meetings with the project team. A solution combining both attitudes could be a kind of way out. It could involve not very frequent, yet regular meetings with the SC, e.g. on a quarterly basis. The further path of project development and the vision of tasks implementation would be discussed then.

\author{
List of abbreviations \\ PM - project manager \\ MP - member of the project \\ HD - Head of Department \\ AC - Area Coordinator \\ SC - Steering Committee
}

\title{
References:
}

BABBIE, E. (2009). Badania społeczne w praktyce (Eng. Social Research in Practice). Warsaw: Wydawnictwo Naukowe PWN.

FISKE, J. (2003). Wprowadzenie do badań nad komunikowaniem (Eng. Introduction to Communication Studies) Wrocław: Astrum.

GRUCZA, B. (2012). Zarządzanie komunikacją w projekcie. W M. Trocki (Ed.) / Communication Management in the Project. W. M. Trotsky (Ed.), Nowoczesne zarządzenie projektami (Eng. Modern Project Management) (pp. 319-327) Warsaw: Polskie Wydawnictwo Ekonomiczne.

JABŁONOWSKI, M., \& MIELCZAREK, T. (2018). Komunikowanie społeczne i media - federacja, a nie inkorporacja. Studia Medioznawcze, (Eng. Social Communication and Media - Federation, not Incorporation. Media Studies).75(4), 13-27.

JAŁOCHA, B. (2014). Zarządzanie portfelem projektów koncepcje biznesowe a praktyka organizacji publicznych (Eng. Project Portfolio Management Business Concepts and Practices of Public Organizations). Cracow: Wydawnictwo Uniwersytetu Jagiellońskiego.

KANDEFER-WINTER, K., \& NADSKAKULSKA, 0. (2016). Komunikacja w zarządzaniu projektami (Eng. Communication in Project Management). Warsaw: CeDeWu.pl.

MADAUSS, B. J. (2000). Handbuch Projektmanagement. Stuttgart: Auflage.

MCLUHAN, M. (2004). Zrozumieć media. Przedłużenie człowieka (Eng. To Understand the Media. Extending the Person). Warsaw: Wydawnictwo Naukowo Techniczne.

MCQUAIL, D. (1987). Mass communication theory: An introduction (2nd ed.). Thousand Oaks, CA, US: Sage Publications.

PAWLAK, M. (2006). Zarządzanie projektami (Eng. Project Management), Warsaw: Wydawnictwo Naukowe PWN.

PRAWELSKA-SKRZYPEK, G. (2011). Zarządzanie projektami jako szansa i wyzwanie dla administracji publicznej. Zeszyty Naukowe WSB we Wrocławiu (Eng. Project Management as an Opportunity and a Challenge for Public Administration. Scientific Papers of the WSB in Wrocław), (26), 195-206.

STASIAK-JAZUKIEWICZ, E., \& JAS-KOZIARKIEWICZ, M. (2011). Polityka Medialna w Unii Europejskiej (Eng. Media Policy in the European Union). Warsaw: Poltext.

TROCKI, M. (Ed.). (2012). Nowoczesne zarządzanie projektami (Eng. Modern Project Management). Warsaw: Polskie Wydawnictwo Ekonomiczne.

TROCKI, M. (Ed.). (2015). Planowanie przebiegu projektów (Eng. Project Planning). Warsaw: Oficyna Wydawnicza SGH.

TURNER, J. R., \& MÜLLER, R. (2004). Communication and co-operation on projects between the project owner as principal and the project manager as agent. European management journal, 22(3), 327-336.

WIMMER, R. D. \& DOMIMICK, J. R. (2006). Mass media Metody badań (Eng. Mass Media Research Methods). Cracow: Wydawnictwo Uniwersytetu Jagiellońskiego.

ZULCH, B. (2014). Leadership communication in project management. Procedia-Social and Behavioral Sciences, 119, 172-181. 